\title{
STUDI PENYEDIAAN AIR BERSIH DI DESA BULOTALANGI TIMUR KECAMATAN BULANGO TIMUR KABUPATEN BONE BOLANGO
}

\author{
Lisma Dara Noropi Yahya ${ }^{1}$, Siti Fatimawati ${ }^{2}$, Sabriana Oktaviana Gintulangi ${ }^{3}$ \\ ${ }^{12}$ Teknik Sipil STITEK Bina Taruna Gorontalo \\ ${ }^{3}$ Sekolah Tinggi Ilmu Administrasi Bina Taruna Gorontalo \\ Indonesia \\ Lismadara1791@gmail.com
}

\begin{abstract}
ABSTRAK
Penelitian ini membahas tentang penyediaan air bersih di Desa Bulotalangi Timur. Tujuan penelitian ini adalah untuk mengetahui kondisi eksisting system penyediaan air bersih dan jumlah kebutuhan air bersih di Desa Bulotalangi Timur. Tahapan pelaksanaan penelitian ini yakni melakukan pengumpulan data primer dan data sekunder. Kemudian dilanjutkan dengan perhitungan jumlah kebutuhan air. Hasil penelitian menunjukkan bahwa kondisi eksisting system penyediaan air bersih di Desa Bulotalangi Timur belum memenuhi persyaratan teknis luas areal dan populasi. Berdasarkan hasil analisis total kebutuhan air pada tahun 2019 sebesar 0,920 liter/detik dan meningkat pada tahun 2023 sebesar 0,977. Untuk fluktuasi Harian Maksimum pada tahun 2019 sebesar 1,150 liter/detik dan meningkat pada tahun 2023 sebesar 1,124 liter. Sedangkan untuk fluktuasi jam puncak pada tahun 2019 sebesar 1,610 liter/detik dan meningkat pada tahun 2023 sebesar 1,710 liter/detik.
\end{abstract}

\section{Kata Kunci: Penyediaan Air Bersih, Fluktuasi Harian Maksimum, Fluktuasi Jam Puncak}

\begin{abstract}
This study discusses about providing clean water prediction in the Bulotalangi Timur Village. The purpose of this study was to determine the existing conditions of the water supply system and the amount of clean water demand in the Bulotalangi Timur Village. This research is conduct by collecting primary data and secondary data. Then proceed with the calculation of the amount of water needed. The results is the existing conditions of clean water supply system in Bulotalangi Timur Village is not appropriate with the technical requirements of the area and population area. Based on the results of the analysis total water demand in 2019 is 0.920 liters / second and increasing in 2023 by 0.977 . For maximum daily fluctuations in 2019 is 1,150 liters / second and increasing in 2023 by 1,124 liters. Peak Hour Fluctuations in 2019 it is 1,610 liters / second and increases in 2023 by 1,710 liters / second.
\end{abstract}

Keywords: Provision of clean water, Maximum Daily Fluctuation, Peak Hour Fluctuation. 


\section{PENDAHULUAN}

Air merupakan unsur yang vital dalam kehidupan manusia. Seseorang tidak dapat bertahan hidup tanpa air, karena itulah air merupakan salah satu penopang hidup bagi manusia. Ketersediaan air di dunia ini begitu melimpah ruah, namun yang dapat dikonsumsi oleh manusia untuk keperluan air minum sangatlah sedikit. Selain itu, kecenderungan yang terjadi sekarang ini adalah berkurangnya ketersediaan air bersih itu dari hari ke hari. Semakin meningkatnya populasi, semakin besar pula kebutuhan akan air minum. Sehingga ketersediaan air bersih pun semakin berkurang. Penyediaan air bersih untuk masyarakat mempunyai peranan yang sangat penting dalam meningkatkan kesehatan lingkungan atau masyarakat, yakni mempunyai peranan dalam menurunkan angka penderita penyakit, khususnya yang berhubungan dengan air, dan berperan dalam meningkatkan standar atau taraf/kualitas hidup masyarakat.

Sampai saat ini, penyediaan air bersih untuk masyarakat di Indonesia masih dihadapkan pada beberpa permasalahan yang cukup kompleks dan sampai saat ini belum dapat diatasi sepenuhnya. Salah satu masalah yang masih dihadapi sampai saat ini yakni masih rendahnya tingkat pelayanan air bersih untuk masyarakat.

Desa Bulotalangi Timur adalah suatu daerah yang berada di Kecamatan Bulango Timur, Kabupaten Bone Bolango yang secara topografi berada di kaki gunung. Desa Bulotalangi Timur terbagi atas 4 dusun dengan luas desa $230 \mathrm{Ha}$ dan jumlah penduduk sebanyak 1011 jiwa pada tahun 2018, yang terbagi menjadi 273 kepala keluarga yang terdiri dari 502 jiwa laki-laki dan 506 jiwa perempuan. Perbandingan jumlah penduduk 5 tahun terakhir yaitu pada tahun 2014 jumlah penduduk Desa Bulotalangi timur berjumlah 908 jiwa dan data terakhir pada tahun 2018 meningkat menjadi 1011 jiwa. Data ini bersumber dari data kependudukan Desa Bulotalangi Timur Tahun 2018. Dengan bertambahnya penduduk di desa tersebut, secara otomatis akan meningkatkan kebutuhan air bersih untuk memenuhi kebutuhan sehari-hari mereka. Oleh karena belum mendapatkan pelayanan air minum dari PDAM, masyarakat Desa Bulotalangi Timur saat ini memanfaatkan mata air terdekat. Mereka memanfaatkan mata air untuk melakukan aktivitas sehari-sehari seperti mencuci baju, MCK, dan lain sebagainya. Aktivitas masyarakat tersebut langsung dilakukan pada mata air. Mata air tersebut berada di sekitar daerah pemukiman.

\section{TUJUAN PENELITIAN}

1. Mengetahui kondisi eksisting sistem penyediaan air bersih di desa Bulotalangi timur.

2. Mengetahui jumlah kebutuhan air bersih di desa Bulotalangi Timur 


\section{TINJAUAN PUSTAKA}

\section{Air bersih}

Air bersih merupakan kebutuhan pokok yang tidak dapat dipisahkan dari kehidupan manusia, sehingga ketersediaannya amatlah penting. Pemanfaatannya tidak hanya terbatas untuk keperluan rumah tangga, tetapi juga untuk fasilitas umum, sosial maupun ekonomi (Khoirillah, 2015).

Kebutuhan air adalah banyaknya jumlah air yang dibutuhkan untuk keperluan rumah tangga, industri, penggelontoran kota dan lain-lain. Prioritas kebutuhan air meliputi kebutuhan air domestik, industri, pelayanan umum dan kebutuhan air untuk mengganti kebocoran (Moegijantoro, 1995).

\section{Sumber-Sumber Air}

\section{a. Air permukaan}

Air permukaan adalah air yang sudah tersedia di alam contohnya sungai, rawa, danau, laut. Pada umumnya air permukaan ini akan mendaapat pengotoran selama pengalirannya, misalnya oleh lumpur, batang-batang kayu, daun-daun, kotoran industri dan sebagainnya. Kekeruhan air permukaan cukup tinggi karena banyak mengandung lempung dan substansi organik.. sehingga ciri air permukaan yaitu memiliki padatan terendap (dissolved solid) rendah, dan bahan tersuspensi (suspended solid) tinggi (Hericah,2015).

\section{Air Sungai}

Air Sungai adalah air hujan yang jatuh kepermukaan bumi dan tidak meresap ke dalam tanah

akan mengalir secara grafitasi searah dengan kemiringan permukaan tanah dan mengalir melewati aliran sungai. Sebagai salah satu sumber air minum, air sungai harus megalami pengolahan secara sempurna karena pada umumnya memiliki derajat pengotoran yang tinggi (Hericah,2015).

\section{Air Danau}

Air danau adalah air permukaan yang berasal dari hujan atau air tanah yang kelar ke permukaan, terkumpul pada suatu tempat yang relative rendah/cekung. Termasuk kategori supaya adalah air rawa, air tendon, air waduk/dam (Hericah,2015).

\section{b. Air Tanah}

Air tanah biasanya mempunyai kualitas yang baik karena zat - zat pencemar air tertahan oleh lapisan tanah (Rida,2014). Bila ditinjau dari kedalaman air tanah maka air tanah dibedakan menjadi air tanah dangkal dan air tanah dalam. Air tanah dangkal mempunyai kualitas lebih rendah dibanding kualitas air tanah dalam. Hal ini disebabkan air tanah dangkal lebih mudah terkontaminasi dari luar dan fungsi tanah sebagai penyaring lebih sedikit (Rida,2014).

\section{c. Air Laut}

Air laut ini mempunyai sifat asin, karena mengandung garam $\mathrm{NaCl}$. Kadar garam $\mathrm{NaCl}$ dalam air laut sebesar 3\%. Dengan demikian untuk menjadikan air laut sebagai sumber air 
bersih haruslah melalui pengolahan khusus (Sutrisno, 1996).

\section{d. Air Hujan}

Air hujan dapat menjadi air minum akan tetapi untuk menjadikan air hujan sebagai air minum hendaknya pada waktu menampung air hujan mulai turun, karena masih megandung banyak kotoran. Selain itu air hujan mempunyai sifat agresif terutama terhadap pipa-pipa penyalur maupun bak-bak reservoir, sehingga hal ini akan mempercepat terjadinya korosi atau karatan (Handayani,2010)

\section{Prinsip Dasar Penyediaan Air Bersih}

Menurut Hericah (2015) penyediaan air bersih harus memenuhi konsep 3K yaitu :

\section{Kualitas air bersih}

Air bersih di pengaruhi oleh bahan baku air itu sendiri atau mutu air tersebut baik yang langsung berasal dari alam atau yang sudah melalui proses pengolahan.

\section{Kuantitas air}

Tergantung jumlah dan ketersediaan air yang akan diolah pada penyediaan air bersih yang dibutuhkan sesuai dengan banyaknya konsumen yang akan dilayani.

\section{Kontinuitas air}

Menyangkut kebutuhan air yang terus menerus digunakan karena air merupakan kebutuhan pokok manusia apalagi air sangat dibutuhkan pada musim kemarau tiba.

\section{a. Kualitas Air}

Air baku yang digunakan menghasilkan air bersih yang telah memenuhi syarat yang tertuang dalam peraturan pemerintah RI No. 82 tahun 2001 tentang pengolahan kualitas air dan pengendalian pencemaran air.

Persyaratan kualitas menggambarkan mutu atau kualitas dari air baku air bersih. Persyaratan ini meliputi persyaratan fisik, persyaratan kimia, persyaratan biologis dan persyaratan radiologis.

\section{b. Kuantitas}

Persyaratan kuantitas dalam penyediaan air bersih dapat ditinjau dari banyaknya air baku yang tersedia. Artinya air baku tersebut dapat digunakan untuk memenuhi kebutuhan sesuai dengan kebutuhan daerah dan jumlah penduduk yang akan dilayani (Nitya, 2014).

Persyaratan kuantitas juga bisa ditinjau dari standar debit air bersih yang dialirkan ke konsumen sesuai dengan jumlah kebutuhan air bersih. Dan kuantitas adalah syarat yang terpenting dalam melayani konsumen agar kebutuhannya sehari-hari berjalan sesuai dengan kemampuan konsumen masing-masing (Nitya, 2014)

\section{c. Kontinuitas}

Kontinuitas aliran dapat ditinjau dari dua aspek yaitu aspek kebutuhan konsumen dan aspek reservoir pelayanan air. Aspek kebutuhan konsumen, sebagian besar konsumen memerlukan air untuk kehidupan dan pekerjaannya dalam jumlah yang tidak dapat ditentukan. Karena itu diperlukan aspek ini pada waktu yang tidak ditentukan. Dan aspek pelayanan reservoir diperlukan karena fasilitas energi reservoir yang siap setiap saat. Sistem pada air baku untuk air bersih harus dapat 
diambil terus menerus dengan fluktuasi debit yang relatif tetap, baik pada saat musim kemarau maupun musim hujan. Kontinuitas dapat diartikan bahwa air bersih harus tersedia 24 jam per hari atau setiap saat diperlukan, kebutuhan air harus tersedia. Akan tetapi kondisi ideal tersebut hampir tidak dapat dipenuhi pada setiap wilayah di Indonesia, sehingga untuk menentukan kontinuitas pemakaian air dapat dilakukan dengan cara pendekatan aktifitas konsumen terhadap pemakaian air

\section{d. Karakteristik kebutuhan}

Air Karakteristik kebutuhan air dibagi menjadi 2 bagian yaitu kebutuhan air sektor domestik dan kebutuhan sektor air non domestik.

\section{Standar Kebutuhan Air Sektor Domestik}

Kebutuhan air domestik merupakan aspek penting dalam menganalisis kebutuhan penyediaan dimasa mendatang. Analisis sektor domestik untuk masa mendatang dilaksanakan degan dasar analisis pertumbuhan penduduk pada wilayah yang direncanakan.

Untuk mengetahui kriteria perencanaan air bersih pada tiap - tiap kategori dapat dilihat pada tabel 1. berikut ini :

\section{Tabel 1. Kriteria Perencanaan Air Bersih}

\begin{tabular}{|c|c|c|c|c|c|}
\hline \multirow{3}{*}{ Uraian } & \multicolumn{5}{|c|}{$\begin{array}{c}\text { Kategori Kota Berdasarkan Jumlah Penduduk } \\
\text { (Jiwa) }\end{array}$} \\
\hline & $>1.000 .000$ & $\begin{array}{c}500.000 \\
s / d \\
1.000 .000\end{array}$ & $\begin{array}{c}100.000 \\
s / d \\
500.000\end{array}$ & $\begin{array}{c}20.000 \\
\text { s/d } \\
100.000\end{array}$ & $<20.000$ \\
\hline & $\begin{array}{c}\text { Kota } \\
\text { Metrop olitan }\end{array}$ & $\begin{array}{l}\text { Kota } \\
\text { Besar }\end{array}$ & $\begin{array}{l}\text { Kota } \\
\text { Sedang }\end{array}$ & $\begin{array}{l}\text { Kota } \\
\text { Kecil }\end{array}$ & Desa \\
\hline 1 & 2 & 3 & 4 & 5 & 6 \\
\hline $\begin{array}{l}\text { 1. Konsumsi Unit Sambungan } \\
\text { Rumah (SR) } \\
\text { (liter/orang/hari) }\end{array}$ & $>150$ & $150-120$ & $90-120$ & $80-120$ & $60-80$ \\
\hline $\begin{array}{l}\text { 2. Konsumsi Unit Hidran } \\
\text { Umum (HU) } \\
\text { (liter/orang/hari) }\end{array}$ & $20-40$ & $21-40$ & $22-40$ & $23-40$ & $24-40$ \\
\hline $\begin{array}{l}\text { 3. konsumsi Unit Non Domestik } \\
\text { a. Niaga Kecil (liter/orang/hari) } \\
\text { b. Niaga Besar (liter/orang/hari) } \\
\text { c. Industri Besar } \\
\text { (liter/orang/hari) } \\
\text { d. Pariwisata (liter/orang/hari) } \\
\end{array}$ & $\begin{array}{c}600-900 \\
1000-5000 \\
0,2-0,8 \\
0,1-0,3\end{array}$ & $\begin{array}{c}600-900 \\
1000-5000 \\
0,2-0,8 \\
0,1-0,4\end{array}$ & & $\begin{array}{c}600-900 \\
1000-5000 \\
0,2-0,8 \\
0,1-0,6\end{array}$ & \\
\hline 4. Kehilangan Air \% & $20-30$ & $20-30$ & $20-30$ & $20-30$ & $20-30$ \\
\hline 5. Faktor Harian Maksimum & $\begin{array}{l}1,15-1,25 \\
\text { *harian }\end{array}$ & $\begin{array}{c}1,15-1,25 \\
\text { *harian }\end{array}$ & $\begin{array}{c}1,15-1,25 \\
\text { *harian }\end{array}$ & $\begin{array}{c}1,15-1,25 \\
\text { *harian }\end{array}$ & $\begin{array}{c}1,15-1,25 \\
\text { *harian }\end{array}$ \\
\hline 6. Faktor Jam Puncak & $\begin{array}{l}1,75-2,0 \\
\text { *hari maks }\end{array}$ & $\begin{array}{l}1,75-2,0 \\
\text { *hari maks }\end{array}$ & $\begin{array}{l}1,75-2,0 \\
\text { *hari maks }\end{array}$ & $\begin{array}{c}1,75 \\
\text { *hari maks }\end{array}$ & $\begin{array}{c}1,75 \\
\text { *hari maks }\end{array}$ \\
\hline 7. Jumlah Jiwa Per SR (Jiwa) & 5 & 5 & 5 & 5 & 5 \\
\hline 8. Jumlah Jiwa Per HU (Jiwa) & 100 & 100 & 100 & $100-200$ & 200 \\
\hline $\begin{array}{l}\text { 9. Sisa Tekan Di Penyediaan } \\
\text { Distribusi (Meter) }\end{array}$ & 10 & 10 & 10 & 10 & 10 \\
\hline 10. Jam Operasi (Jam) & 24 & 24 & 24 & 24 & 24 \\
\hline $\begin{array}{l}\text { 11. Volume Reservoir ( } \% \text { Max } \\
\text { Day Deman) }\end{array}$ & $15-25$ & $15-25$ & $15-25$ & $15-25$ & $15-25$ \\
\hline 12. SR : HU & $\begin{array}{c}50: 50 \\
\text { s/d } \\
80: 80 \\
\end{array}$ & $\begin{array}{c}50: 50 \\
\text { s/d } \\
80: 80 \\
\end{array}$ & $80: 20$ & $70: 30$ & $70: 30$ \\
\hline 13. Cakupan Pelayanan & 90 & 90 & 90 & 90 & 70 \\
\hline
\end{tabular}


Menurut kriteria perencanaan Ditjen

Cipta Karya Dinas Pu,1996 Maka :

a. Konsumsi sambungan rumah tangga : 70 liter/orang/hari.

b. Konsumsi sambungan hidran umum adalah : 30 liter/orang/hari.

c. Perbandingan antara sambungan rumah tangga dan hidran umum adalah : SR : $\mathrm{HU}=70: 30$

2. Standar Kebutuhan Air Sektor Non Domestik

Standar kebutuhan air non domestik adalah kebutuhan air di luar kebutuhan rumah tangga, seperti : sekola, rumah sakit, kantor, pasar serta fasilitas lainnya. Kebutuhan non domestik terbagi menjadi beberapa kategori yang di tunjukkan pada Tabel 2, Tabel 3 dan 4.

Tabel 2. Kebutuhan Air Non Domestik Untuk Kota Kategori I, II, III, IV

\begin{tabular}{|l|l|l|}
\hline SEKTOR & NILAI & SATUAN \\
\hline Sekolah & 10 & liter/murid hari \\
Rumah Sakit & 200 & liter/ bed hari \\
Puskesmas & 2000 & liter/ unit hari \\
Masjid & 3000 & liter/unit hari \\
Kantor & 10 & liter/pegawai hari \\
Pasar & 12000 & liter hektar hari \\
Hotel & 150 & liter bed hari \\
Rumah Makan & 100 & liter tempat duduk hari \\
Kompleks Militer & 60 & iter/orang hari \\
Kawasan Industri & $0,2-0,8$ & liter/detik hektar \\
Kawasan Pariwisata & $0,1-0,3$ & liter/detik hektar \\
\hline
\end{tabular}

Sumber : Kriteria Perencanaan Ditjen Cipta Karya Dinas PU, 1996
Tabel 3. Kebutuhan Air Non Domestik Untuk Kategori V ( Desa )

\begin{tabular}{|l|l|l|}
\hline SEKTOR & NILAI & SATUAN \\
\hline Sekolah & 5 & liter murid hari \\
Rumah Sakit & 200 & liter bed hari \\
Puskesmas & 1200 & liter unithari \\
Masjid & 3000 & liter unithari \\
Musholla & 2000 & Liter unit hari \\
Pasar & 12000 & Liter hektar hari \\
Komersial / Industri & 10 & Liter hari \\
\hline
\end{tabular}

Tabel 4. Kebutuhan Air Non Domestik Untuk Kategori Lain

\begin{tabular}{|l|l|l|}
\hline SEKTOR & NILAI & SATUAN \\
\hline Lapangan Terbang & 10 & liter/orang/detik \\
Pelabuhan & 50 & liter/orang/detik \\
Stasiun KA dan Terminal bus & 10 & liter/orang/detik \\
Kawasan Industri & 0,75 & liter/detik hektar \\
\hline \multicolumn{2}{|l|}{ Sumber : Kriteria Perencanaan Ditjen Cipta Karya Dinas PU, 1996. }
\end{tabular}

\section{METODELOGI PENELITIAN}

Lokasi Penelitian Desa Bulotalangi Timur adalah suatu daerah yang berada di Kecamatan Bulango Timur, Kabupaten Bone Bolango Provinsi gorontalo yang secara geografis di batasi oleh :

Sebelah Utara : Desa Langge dan Meranti

Sebelah Barat : Desa Bulotalangi

Sebelah Selatan: Desa Bulotalangi

Sebelah Timur : Desa Lonuo Dan Tamboo

\section{Alat dan Bahan Penelitian}
a. GPS
b. Kamera
c. Peta lokasi
d. Dan lain-lain 


\section{Teknik Pengumpulan Data}

\section{a. Jenis-Jenis Data}

Adapun data yang digunakan dalam penulisan ini adalah data primer, dan data sekunder. Data data yang dikumpulkan terdiri atas :

1. Data primer adalah data yang diperoleh secara langsung di lapangan dengan metode survey, data ini berupa :

a. Observasi lapangan yaitu dengan melihat dan mendokumentasikan kondisi eksisting sistem penyediaan air bersih di lokasi penelitian.

b. Wawancara penduduk yang ada di Desa Bulotalangi Timur mengenai permasalahan penyediaan air bersih. Wawancara mengenai jumlah jiwa dalam keluarga dan sumber air yang digunakan.

2. Data sekunder yaitu diperolehdari instansi yang terkait seperti: kantor Desa, serta data yang lainnya yang mendukung dalam penelitian ini. Adapun data sekunder meliputi :

a. Peta lokasi Penelitian

Peta lokasi penelitian bertujuan untuk melihat lokasi desa Bulotalangi Timur Kecamatan Bolango Timur Kabupaten Bone Bolango

b. Data Jumlah Penduduk Data jumlah penduduk digunakan untuk memproyeksikan jumlah penduduk dan kebutuhan air di dasa Bulotalangi Timur.

\section{b. Prosedur Penelitian}

Untuk melakukan penelitian, langkah pertama yang dilakukan yaitu mengetahui karakteristik penyediaan air bersih dengan melakukan observasi loksi wilayah yaitu dengan melihat kondisi eksisting penyediaan air bersih serta permasalahan - permasalahan yang ada dengan menganalisa kebutuhan air bersih di desa bulotalangi timur. Adapun langkah melakukan survey yaitu :

a. Melakukan survey lokasi dan mengambil dokumentasi sumber-sumber air.

b. Mengamati permasalahan - permasalahan penyediaan air bersih yang ada di lokasi dengan melakukan wawancara kepada penduduk setempat.

c. Mewawancarai penduduk dengan mengambil 5 sampel secara acak di setiap dusun yang ada di desa Bulotalangi Timur dengan total sampel sebanyak 20 sampel.

d. Mengumpulkan data jumlah penduduk dari instansi terkait dari tahun 2014 sampai tahun 2018.

\section{Teknik Pengolahan Data}

Dalam tahapan pengolahan data langkah awal yang dilakukan yaitu mengetahui kondisi eksisting sistem penyediaan air bersih yang ada di Desa Bulotalangi Timur , kemudian dilanjutkan dengan menghitung kebutuhan air di desa Bulotalangi Timur, serta solusi untuk memeksimalkan penyediaan air bersih, dengan menghitung kebutuhan air bersih dibagi menjadi 
2 bagian yaitu kebutuhan domestik dan non domestik. Adapun langkah - langkah untuk pengolahan data dengan tahap sebagai berikut :

\section{a. Perhitungan Jumlah Penduduk}

Perhitungan jumlah penduduk menggunakan metode Geometri dengan asumsi penduduk akan bertambah/berkurang pada suatu tingkat pertumbuhan (persentase) yang tetap. Metode geometrik dalam proyeksi pertumbuhan penduduk dapat dihitung dengan menggunakan rumus berikut :

$\mathrm{Pn}=\mathrm{Po}(1+\mathrm{r}) \mathrm{n}$

Dimana:

Pn = Jumlah Pertumbuhan Penduduk pada tahun ke $n$

Po $=$ Jumlah Penduduk tahun awal

$\mathrm{r}$ = Laju Pertumbuhan Penduduk (\%)

$\mathrm{n}=$ jumlah interval

\section{b. Perhitungan Kebutuhan Air}

Dalam perhitungan kebutuhan air domestik dan non domestik didasarkan pada jumlah kebutuhan air keseluran. Kebutuhan air domestik dan non domestik diproyeksikan 5 tahun mendatang.

\section{a. Kebutuhan air domestik}

Kebutuhan air domestik yaitu menghitung kebutuhan airuntuk sambungan rumah (SR) dan hidran umum (HU). Contoh tabel perhitungan kebutuhan air domestik ditunjukkan pada tabel 5.

Tabel 5. Contoh Tabel Kebutuhan Air Domestik Untuk Sambungan Rumah (SR)

\begin{tabular}{|c|c|c|c|c|c|c|c|}
\hline No & Tahun & $\begin{array}{c}\text { Jumlah } \\
\text { Penduduk } \\
\text { (jiwa) }\end{array}$ & $\begin{array}{c}\text { Tingkat } \\
\text { Pelayanan } \\
(\%)\end{array}$ & $\begin{array}{c}\text { Jumlah } \\
\text { Terlayani } \\
\text { (Jiwa) }\end{array}$ & $\begin{array}{c}\text { Konsumsi Air } \\
\text { Rata-Rata } \\
\text { (Lt juiwa hari) }\end{array}$ & $\begin{array}{c}\text { Jumlah } \\
\text { Pemakaian } \\
(\mathrm{Lt} / \text { Hari) }\end{array}$ & $\begin{array}{c}\text { Jumlah } \\
\text { Kebutuhan Air } \\
\text { (Liter / Dtk) }\end{array}$ \\
\hline$[\mathrm{a}]$ & {$[\mathrm{b}]$} & {$[\mathrm{c}]$} & {$[\mathrm{d}]$} & {$[\mathrm{e}]$} & {$[\mathrm{f}]$} & {$[\mathrm{g}]$} & {$[\mathrm{h}]$} \\
\hline & & & & & & & \\
\hline & & & & & & & \\
\hline & & & & & & & \\
\hline & & & & & & & \\
\hline & & & & & & & \\
\hline
\end{tabular}

Keterangan :

[a] $=$ Nomor Urut

$[\mathrm{b}]=$ Tahun Proyeksi (tahun perencanaan)

$[\mathrm{c}]=$ hasil perhitungan proyeksi penduduk

[d] = tabel 1 no. 13 kolom 6 (desa)

$[\mathrm{e}]=[\mathrm{c}] \mathrm{x}[\mathrm{d}]$

[f] = kriteria perencanaan Ditjen Cipta Karya Dinas PU

$$
[\mathrm{g}]=[\mathrm{e}] \mathrm{x}[\mathrm{f}]
$$

$[\mathrm{h}]=[\mathrm{g}] /(24 \times 60 \times 60)$

\section{b. Kebutuhan Air Non Domestik}

Kebutuhan air non domestik yaitu menghitung kebutuhan air untuk fasilitas seperti fasilitas pendidikan, fasilitas kesehatan, fasilitas perkantoran serta fasilitas lainnya. Contoh kebutuhan air non domestik untuk fasilitas pendidikan ditunjukkan pada tabel 6 .

Tabel 6. Contoh Tabel Kebutuhan Air Non Domestik Untuk Fasilitas Pendidikan

\begin{tabular}{|c|c|c|c|c|c|}
\hline No & Tahun & $\begin{array}{c}\text { Jumlah } \\
\text { Pelajar } \\
\text { (otang) }\end{array}$ & $\begin{array}{c}\text { Konsumsi air } \\
\text { Rata }- \text { rata } \\
\text { (Lt/orang/hari) }\end{array}$ & $\begin{array}{c}\text { Jumlah } \\
\text { Pemakaian } \\
\text { (Lthari) }\end{array}$ & $\begin{array}{c}\text { Jumlah } \\
\text { Kebutuhan air } \\
\text { (Liter/detik) }\end{array}$ \\
\hline$[\mathrm{a}]$ & {$[\mathrm{b}]$} & {$[\mathrm{c}]$} & {$[\mathrm{d}]$} & {$[\mathrm{e}]$} & {$[\mathrm{f}]$} \\
\hline & & & & & \\
\hline & & & & & \\
\hline & & & & & \\
\hline & & & & & \\
\hline & & & & & \\
\hline
\end{tabular}

Keterangan :

[a] $=$ Nomor Urut

$[\mathrm{b}]=$ Tahun Proyeksi (tahun perencanaan)

[c] = Jumlah pelajar pada tahun yang diproyeksikan

$[\mathrm{d}]=$ kriteria perencanaan Ditjen Cipta Karya Dinas PU

$[\mathrm{e}]=[\mathrm{c}] \mathrm{x}[\mathrm{d}]$

$[\mathrm{f}]=[\mathrm{e}] /(24 \times 60 \times 60)$

c. Kebutuhan Air Bersih di Desa Bulotalangi Timur

Kebutuhan air di Desa Bulotalangi

Timur yaitu jumlah kebutuhan air normal di

Desa Bulotalangi Timur. Contoh tabel 
kebutuhan air bersih di Desa Bulotalangi

Timur di tunjukkan pada Tabel 7.

Tabel 7. Contoh Kebutuhan Air Di Desa Bulotalangi Timur

\begin{tabular}{|c|c|c|c|c|c|c|c|}
\hline Tahun & $\begin{array}{c}\text { SR } \\
(1 t / d t k)\end{array}$ & $\begin{array}{c}\mathrm{HU} \\
(\mathrm{lt} d \mathrm{dtk})\end{array}$ & $\begin{array}{l}\text { Pendidikan } \\
\text { (ltddtk) }\end{array}$ & \begin{tabular}{|c|} 
Peribadatan \\
Mesjid \\
(lt/dtk)
\end{tabular} & $\begin{array}{c}\text { Perkantoran } \\
\text { (1t/dtk) }\end{array}$ & $\begin{array}{l}\text { Puskesmas } \\
\text { (ltddk) }\end{array}$ & $\begin{array}{l}\text { Jumlah } \\
\text { (ltddk) }\end{array}$ \\
\hline \multicolumn{8}{|l|}{\begin{tabular}{|l|}
2018 \\
\end{tabular}} \\
\hline \multicolumn{8}{|l|}{2019} \\
\hline \multicolumn{8}{|l|}{2020} \\
\hline \multicolumn{8}{|l|}{\begin{tabular}{|l|}
2021 \\
\end{tabular}} \\
\hline 2022 & & & & & & & \\
\hline
\end{tabular}

\section{d. Rekapitulasi Kebutuhan Air Bersih di Desa Bulotalangi Timur}

Rekapitulasi kebutuhan air bersih di Desa Bulotalangi Timur yaitu jumlah kebutuhan air untuk waktu normal, faktor harian maksimum, dan faktor jam puncak. Contoh tabel rekapitulasi kebutuhan air bersih di desa Bulotalangi Timur ditunjukkan pada tabel 8 .

Tabel 8. Rekapitulasi Kebutuhan Air Bersih Di Desa Bulotalangi Timur

\begin{tabular}{|c|c|c|c|c|c|c|}
\hline & Faktor & 2019 & 2020 & 2021 & 2022 & 2023 \\
\hline $\begin{array}{c}\text { Normal } \\
\text { (ltr/dtk) }\end{array}$ & 1 & & & & & \\
\hline $\begin{array}{c}\text { FHM } \\
\text { (ltr/dtk) }\end{array}$ & 1,15 & & & & & \\
\hline $\begin{array}{c}\text { FJP } \\
\text { (ltr/dtk) }\end{array}$ & 1,75 & & & & & \\
\hline
\end{tabular}

\section{HASIL PENELITIAN}

\section{Sistem Jaringan Air Bersih}

Informasi data sekunder yang didapat yaitu sistem penyediaan air bersih yang berada di Desa Bulotalangi Timur masih kurang memenuhi, dikarenakan yang terlayani pada masyarakat hanya sebesar \pm 20 s/d $40 \%$. Kapasitas produksi keseluruhan instalasi pengolahan air bersih yang ada hanya dapat melayani 47 kepala keluarga dari total 275 kepala keluarga yang ada di Desa Bulotalangi Timur. Sumbar instalasi pengolahan air bersih yang ada di Desa Bulotalangi Timur sampai 2018 yaitu sebanyak 1 unit mata air yang di kelola oleh PAMSIMAS.

a. Kondisi Eksisting Sistem Penyedian Air Bersih Hasil Survai

Kondisi sistem penyediaan air bersih di Desa Bulotalangi Timur Kecamatan Bulango Timur Kabupaten Bone Bolango ditunjukkan pada Tabel 9.

Tabel 9. Kondisi Eksisting Sistem Penyediaan Air Bersih di Desa Bulotalangi Timur

\begin{tabular}{|c|c|c|c|c|l|}
\hline No & Wilayah & $\begin{array}{c}\text { Sumber Air } \\
\text { Bersih }\end{array}$ & Pasokan Air & $\begin{array}{c}\text { Kualitas } \\
\text { Air Bersih }\end{array}$ & Keterangan \\
\hline 1 & Dusun I & $\begin{array}{l}\text { Sumur pompa, } \\
\text { sumur gali, } \\
\text { Hidran umum }\end{array}$ & $\begin{array}{c}\text { Cukup stabil } \\
\text { \&lancar }\end{array}$ & Cukup & $\begin{array}{l}\text { sebagian kering } \\
\text { saat musim } \\
\text { kemarau }\end{array}$ \\
\hline 2 & Dusun II & $\begin{array}{l}\text { Sumur pompa, } \\
\text { Sumur Gali }\end{array}$ & $\begin{array}{c}\text { Cukup stabil } \\
\text { \& lancar }\end{array}$ & Cukup & $\begin{array}{l}\text { sebagian kering } \\
\text { saat musim } \\
\text { kemarau }\end{array}$ \\
\hline 3 & Dusun III & $\begin{array}{l}\text { Sumur pompa, } \\
\text { sumur gali, mata } \\
\text { air, hidran umum }\end{array}$ & $\begin{array}{c}\text { Tidak stabil } \\
\& \text { tidak } \\
\text { lancar }\end{array}$ & Buruk & $\begin{array}{l}\text { sebagian kering } \\
\text { saat musim } \\
\text { kemarau }\end{array}$ \\
\hline 4 & Dusun IV & $\begin{array}{l}\text { Sumur pompa, } \\
\text { sumur gali, mata } \\
\text { air, hidran umum }\end{array}$ & $\begin{array}{c}\text { Tidak stabil } \\
\& \text { tidak } \\
\text { lancar }\end{array}$ & Buruk & $\begin{array}{l}\text { sebagian kering } \\
\text { saat musim } \\
\text { kemarau }\end{array}$ \\
\hline
\end{tabular}

Berdasarkan Tabel 9 menunjukkan kondisi eksisting sistem penyediaan air bersih di Desa Bulotalangi Timur memiliki masalah yaitu sistem penyediaan air bersih belum bisa memenuhi untuk kebutuhan sehari-hari. Pada Dusun III dan IV masyarakat menggunakan mata air PAMSIMAS serta sumur pompa sebagai sumber air bersih, akan tetapi pasokan air bersih belum terpenuhi dikarenakan PAMSIMAS hanya bisa menjangkau masyarakat sekitar sumbaer air saja, sedangkan sumur pompa terkadang kering pada musim kemarau. Masalah yang terdapat pada dusun I dan II Desa Bulotalangi Timur yaitu sumber air yang digunakan hanya sumur gali, hidran umum dan sumur pompa, adapun jaringan PDAM tidak bisa digunakan dikarenakan umur pipa lebih dari 
10 tahun tidak terpakai. Masalah yang terdapat pada Dusun II, III dan IV Desa Bulotalangi Timur masyarakat menggunakan sumur sebagai sumber air bersih yang rata-rata kedalamannya mencapai 10 meter, serta sumur pompa yang kedalaman rata-rata mencapai 28 meter, akan tetapi saat musim kemarau sumur-sumur tersebut mengalami kekeringan sehingga pemerintah setempat mengupayakan mobil tengki air untuk memenuhi kebutuhan air di Desa Bulotalangi timur.

\section{b. Analisis Penyediaan Air Bersih}

Untuk memenuhi sistem penyediaan air bersih pada lokasi penelitian terdapat beberapa variabel yaitu analisis pertumbuhan penduduk, perhitungan proyeksi jumlah penduduk, analisis kebutuhan air sektor domestik, serta analisis kebutuhan air sektor non domestik.

\section{Analisis pertumbuhan penduduk}

Analisis pertumbuhan penduduk di Desa Bulotalangi Timur adalah memberikan data penduduk. Dari data tersebut kemudian dihitung tingkat pertumbuhan tiap tahunnya dengan menggunakan metode Geometrik. Setelah rasio pertumbuhan, kemudian memproyeksikan pertumbuhan penduduk pada tahun 2019 sampai dengan tahun 2023. Data jumlah penduduk desa bulotalangi Timur ditunjukkan pada tabel 10 .

Tabel 10. Jumlah Penduduk Desa Bulotalangi Timur

\begin{tabular}{|c|c|c|}
\hline No & Tahun & Jumlah Penduduk \\
\hline 1 & 2014 & 908 \\
\hline 2 & 2015 & 942 \\
\hline 3 & 2016 & 965 \\
\hline 4 & 2017 & 1003 \\
\hline 5 & 2018 & 1011 \\
\hline
\end{tabular}

Sumber : Laporan Kependudukan Desa Bulotalangi Timur, 2019
Berdasarkan Tabel 10 jumlah penduduk Desa Bulotalangi Timur mengalami peningkatan dari tahun ke tahun. Tercatat bahwa jumah penduduk Desa Bulotalangi Timur pada tahun 2014 adalah sebesar 908 jiwa dan meningkat menjadi 1011 jiwa pada tahun 2018 atau meningkat dengan pertumbuhan rata-rata sebesar 2,17 atau $0,02 \%$ berdasarkan perhitungan :

$$
r=\left(\frac{p_{t} \frac{1}{t}}{p_{0}}\right)-1
$$

Dimana :

$\mathrm{Pt}=$ jumlah penduduk pada tahun $\mathrm{t}$

$\mathrm{Po}=$ jumlah penduduk pada tahun dasar

$\mathrm{T}=$ jangka waktu

$\mathrm{r}$ = laju pertumbuhan penduduk

$$
r=\left(\frac{1011}{908}\right)^{\frac{1}{5}}-1=0,02 \text { atau } 2,17 \%
$$

\section{a. Perhitungan proyeksi jumlah penduduk tahun 2019-2023}

Setelah mendapatkan rasio pertumbuhan menggunakan metode geometrik kemudian dilanjutkan dengan menghitung proyeksi penduduk Desa Bulotalangi Timur pada tahun 2019 sampai 2023. Adapun formula yang digunakan sebagai berikut :

Formula yang digunakan yaitu :

$\mathrm{Pn}=\mathrm{P} 0(1+\mathrm{r}) \mathrm{n}$

Dimana :

Pn $=$ jumlah penduduk pada tahun ke $n$

$\mathrm{P} 0=$ jumlah penduduk pada tahun awal

$r=$ laju pertumbuhan penduduk

$\mathrm{n}=$ jumlah interval

Berikut adalah contoh perhitungan di Desa Bulotalangi Timur untuk tahun 2023.

Penyelesaian :

Pn $=1011(1+0,02) 5=1116$ Dimana :

$\mathrm{P} 0=$ jumlah penduduk pada tahun 2018 yaitu

$\mathrm{r}=$ rasio diperoleh yaitu 0,02 
$\mathrm{n}=5$ Untuk hasil analisis Desa Bulotalangi Timur dapat di tunjukkan pada tabel 11.

Tabel 11. Proyeksi Pertumbuhan Penduduk Desa Bulotalangi Timur

\begin{tabular}{|c|c|c|}
\hline No & Tahun & Jumlah Penduduk \\
\hline 1 & 2019 & 1031 \\
\hline 2 & 2020 & 1052 \\
\hline 3 & 2021 & 1073 \\
\hline 4 & 2022 & 1094 \\
\hline 5 & 2023 & 1116 \\
\hline
\end{tabular}

Berdasarkan Tabel 11 menunjukkan proyeksi jumlah penduduk dari tahun 2019 sampei dengan tahun 2023 mengalami peningkatan. Pada tahun 2019 jumlah penduduk Desa Bulotalangi Timur sebesar 1031 jiwa dan pada tahun 2023 meningkat yaitu 1116 jiwa.

\section{b. Analisis kebutuhan air sektor domestik}

Perhitungan kebutuhan air domestik adalah perhitungan jumlah air di Desa Bulotalangi Timur yang digunakan untuk rumah tangga untuk memenuhi kebutuhan sehari-hari seperti : mandi, mencuci memasak dan keperluan rumah tangga lainnya. Kebutuhan air domestik antara lain :

\section{Sambungan Rumah Tangga (SR)}

Kebutuhan air di Desa Bulotalangi Timur menggunakan perbandingan antara sambungan rumah dan hidran umum adalah 70 : 30. Hasil analisis Sambungan Rumah (SR) di Desa Bulotalangi Timur di tunjukkan pada tabel 12.

\begin{tabular}{|c|c|c|c|c|c|c|c|}
\hline No & Tahun & $\begin{array}{c}\text { Jumlah } \\
\text { Penduduk } \\
\text { (jiwa) }\end{array}$ & $\begin{array}{c}\text { Tingkat } \\
\text { Pelayanan } \\
(\%)\end{array}$ & $\begin{array}{c}\text { Jumlah } \\
\text { Terlayani } \\
\text { (Jiwa) }\end{array}$ & $\begin{array}{c}\text { Konsumsi Air } \\
\text { Rata-Rata } \\
\text { (Ltjiwa/hari) }\end{array}$ & $\begin{array}{c}\text { Jumlah } \\
\text { Pemakaian } \\
\text { (Lt/Hari) }\end{array}$ & $\begin{array}{c}\text { Jumlah } \\
\text { Kebutuhan Air } \\
\text { (Liter/Dtk) }\end{array}$ \\
\hline [a] & {$[\mathrm{b}]$} & {$[\mathrm{c}]$} & {$[\mathrm{d}]$} & {$[\mathrm{e}]$} & {$[\mathrm{f}]$} & {$[\mathrm{g}]$} & {$[\mathrm{h}]$} \\
\hline 1 & 2019 & 1031 & 70 & 722 & 70 & 50540 & 0,585 \\
\hline 2 & 2020 & 1052 & 70 & 736 & 70 & 51520 & 0,596 \\
\hline 3 & 2021 & 1073 & 70 & 751 & 70 & 52570 & 0,609 \\
\hline 4 & 2022 & 1094 & 70 & 766 & 70 & 53620 & 0,621 \\
\hline 5 & 2023 & 1116 & 70 & 781 & 70 & 54670 & 0,633 \\
\hline
\end{tabular}

Keterangan :

[a] = Nomor Urut

$[\mathrm{b}]=$ Tahun Proyeksi (tahun perencanaan)

$[\mathrm{c}]=$ hasil perhitungan proyeksi penduduk

[d] \& [f] = Kriteria perencanaan sesuai kebutuhan masyarakat di Desa Bulotalangi Timur yaiti SR : Hu \& $70: 30$

$[\mathrm{e}]=[\mathrm{c}] \mathrm{x}[\mathrm{d}]$

$[\mathrm{g}]=[\mathrm{e}] \mathrm{x}[\mathrm{f}]$

$[\mathrm{h}]=[\mathrm{g}] /(24 \times 60 \times 60)$

Berdasarkan tabel 12 kebutuhan air di Desa Bulotalangi Timur, untuk kebutuhan air sambungan rumah (SR) pada tahun 2019 sebesar 0,585 liter/detik kemudian meningkat pada tahun 2023 sebesar 0,633 liter/detik.

\section{Hidran umum}

Kebutuhan air di Desa Bulotalangi Timur menggunakan perbandingan antara sambungan rumah dan hidran umum adalah $\mathrm{SR}: \mathrm{HU}=70$ : 30. Hasil analisis kebutuhan air hidran umum Desa Bulotalangi Timur ditunjukkan pada tabel 13.
Tabel 12. Kebutuhan Air SR Desa Bulotalangi Timur
Tabel 13. Kebutuhan Air HU Desa Bulotalangi Timur 


\begin{tabular}{|c|c|c|c|c|c|c|c|}
\hline No & Tahun & $\begin{array}{c}\text { Jumlah } \\
\text { Penduduk } \\
(\text { Jiwa })\end{array}$ & $\begin{array}{c}\text { Tingkat } \\
\text { Pelayanan } \\
(\%)\end{array}$ & $\begin{array}{c}\text { Jumla } \\
\text { Terlayani } \\
(\text { Jiva })\end{array}$ & $\begin{array}{c}\text { Konsumsi air } \\
\text { Rata-Rata } \\
\text { (Ltjina hari) }\end{array}$ & $\begin{array}{c}\text { Jumlah } \\
\text { Pemakaian } \\
(\text { LtHari) }\end{array}$ & $\begin{array}{c}\text { Jumlah } \\
\text { Kebutuhan Air } \\
\text { (Liter Detik) }\end{array}$ \\
\hline$[\mathrm{a}]$ & {$[\mathrm{b}]$} & {$[\mathrm{c}]$} & {$[\mathrm{d}]$} & {$[\mathrm{e}]$} & {$[\mathrm{f}]$} & {$[\mathrm{g}]$} & {$[\mathrm{h}]$} \\
\hline 1 & 2019 & 1031 & 30 & 309 & 30 & 9270 & 0,107 \\
\hline 2 & 2020 & 1052 & 30 & 316 & 30 & 9480 & 0,110 \\
\hline 3 & 2021 & 1073 & 30 & 322 & 30 & 9660 & 0,112 \\
\hline 4 & 2022 & 1094 & 30 & 328 & 30 & 9840 & 0,114 \\
\hline 5 & 2023 & 1116 & 30 & 335 & 30 & 10050 & 0,116 \\
\hline
\end{tabular}

Keterangan :

$[\mathrm{a}]=$ Nomor urut

$[\mathrm{b}]=$ Tahun proyeksi (tahun perencanaan)

[c] = Hasil perhitungan proyeksi penduduk (tabel

[d] \& [f] = Kriteria perencanaan sesuai kebutuhan masyarakat Desa Bulotalangi Timur yaitu SR : HU \& $70: 30$

$[\mathrm{e}]=[\mathrm{c}] \times[\mathrm{d}]$

$[\mathrm{g}]=[\mathrm{e}] \mathrm{x}[\mathrm{f}]$

$[\mathrm{h}]=[\mathrm{g}] /(24 \times 60 \times 60)$

\section{Berdasarkan Tabel 13 Menunjukkan}

kebutuhan air Hidran Umum (HU) di Desa Bulotalangi Timur pada tahun 2019 yaitu sebesar 0,107 liter/detik kemudian meningkat pada tahun 2023 sebesar 1,116 liter/detik.

\section{c. Analisis kebutuhan air sektor non domestic}

Kebutuhan air sektor non domestik yaitu kebutuhan air yang diperlukan diluar kebutuhan rumah tangga, kebutuhan air non domestik terdiri dari fasilitas pendidikan, fasilitas peribadatan, fasilitas perkantoran, fasilitas kesehatan serta fasilitas lainnya. Dalam menghiting kebutuhan air sektor non domestik tergantung pada fasilitas yang ada di Desa Bulotalangi Timur. Berikut adalah hasil analisis perhitungan kebutuhan air sektor non domestik :

\section{Fasilitas pendidikan}

Fasilitas pendidikan di Desa Bulotalangi Timur ada 3 yakni RA Al - Hidayah, MI Al -
Hidayah, dan MTs Al - Hidayah. Data jumlah pelajar di peroleh dari jumlah siswa, tenaga pendidik dan operator yang ada pada fasilitas pendidikan tersebut. Berikut adalah hasil analisis untuk fasilitas pendidikan di Desa Bulotalangi Timur yang di tunjukkan pada Tabel 14 .

a. Fasilitas pendidikan RA. Al - Hidayah

Tabel 14. Kebutuhan air fasilitas pendidikan RA. Al - Hidayah Desa Bulotalangi Timur

\begin{tabular}{|c|c|c|c|c|c|}
\hline No & Tahun & $\begin{array}{c}\text { Jumlah } \\
\text { Pelajar } \\
\text { (Orang) }\end{array}$ & $\begin{array}{c}\text { Konsumsi Air } \\
\text { Rata-Rata } \\
\text { (Ltoranghari) }\end{array}$ & $\begin{array}{c}\text { Jumlah } \\
\text { Pemakaian } \\
\text { (Lthari) }\end{array}$ & $\begin{array}{c}\text { Jumlah } \\
\text { Kebutuhan Air } \\
\text { (Liter/Detik) }\end{array}$ \\
\hline$[\mathrm{a}]$ & {$[\mathrm{b}]$} & {$[\mathrm{c}]$} & {$[\mathrm{d}]$} & {$[\mathrm{e}]$} & {$[\mathrm{f}]$} \\
\hline 1 & 2019 & 32 & 5 & 160 & 0,02 \\
\hline 2 & 2020 & 33 & 5 & 165 & 0,02 \\
\hline 3 & 2021 & 34 & 5 & 170 & 0,02 \\
\hline 4 & 2022 & 35 & 5 & 175 & 0,02 \\
\hline 5 & 2023 & 36 & 5 & 180 & 0,02 \\
\hline
\end{tabular}

Keterangan :

$[\mathrm{a}]=$ Nomor urut

[b] = Tahun proyeksi (tahun perencanaan)

[c] = Jumlah pelajar tahun 2018 yaitu diperoleh dari sekolah RA. Al- Hidayah Desa Bulotalangi Timur. Perhitungan proyeksi pelajar dihitung menggunakan metode geometrik

$[\mathrm{d}]=$ Tabel 3

$[\mathrm{e}]=[\mathrm{c}] \mathrm{x}[\mathrm{d}]$

$[\mathrm{f}]=[\mathrm{e}] /(24 \times 60 \times 60$

Berdasarkan hasil analisis pada tabel 14 Menunjukkan bahwa pada RA. Al - Hidayah Desa Bulotalangi Timur, untuk Fasilitas pendidikan pada tahun 2019 sampai dengan 2023 belum mengalami penungkatan atau konstan yaitu sebesar 0,02 liter/detik

\section{b. Fasilitas pendidikan MI. Al Hidayah}

Tabel 15. Kebutuhan Air Fasilitas Pendidikan MI. Al - Hidayah Desa Bulotalangi Timur 


\begin{tabular}{|c|c|c|c|c|c|}
\hline No & Tahun & $\begin{array}{c}\text { Jumlah } \\
\text { Pelajar } \\
\text { (Orang) }\end{array}$ & $\begin{array}{c}\text { Konsumsi Air } \\
\text { Rata-Rata } \\
\text { (Ltorang hari) }\end{array}$ & $\begin{array}{c}\text { Jumlah } \\
\text { Pemakaian } \\
\text { (Lthari) }\end{array}$ & $\begin{array}{c}\text { Jumlah } \\
\text { Kebutuhan Air } \\
\text { (Liter/Detik) }\end{array}$ \\
\hline$[\mathrm{a}]$ & {$[\mathrm{b}]$} & {$[\mathrm{c}]$} & {$[\mathrm{d}]$} & {$[\mathrm{e}]$} & {$[\mathrm{f}]$} \\
\hline 1 & 2019 & 99 & 5 & 495 & 0,06 \\
\hline 2 & 2020 & 104 & 5 & 520 & 0,06 \\
\hline 3 & 2021 & 109 & 5 & 545 & 0,06 \\
\hline 4 & 2022 & 114 & 5 & 570 & 0,07 \\
\hline 5 & 2023 & 120 & 5 & 600 & 0,07 \\
\hline
\end{tabular}

Keterangan :

[a] $=$ Nomor urut

$[\mathrm{b}]=$ Tahun proyeksi (tahun perencanaan)

[c] = Jumlah pelajar tahun 2018 yaitu diperoleh dari sekolah MI. Al- Hidayah Desa Bulotalangi Timur. Perhitungan proyeksi pelajar dihitung menggunakan metode geometric

$[\mathrm{d}]=$ Tabel 3

$[\mathrm{e}]=[\mathrm{c}] \mathrm{x}[\mathrm{d}]$

$[\mathrm{f}]=[\mathrm{e}] /(24 \times 60 \times 60)$

Berdasarkan hasil analisis pada tabel 15 Menunjukkan bahwa pada MI. Al - Hidayah Desa Bulotalangi Timur, untuk Fasilitas pendidikan pada tahun 2019 jumlah kebutuhan air 0,06 liter/detik kemudian meningkat pada tahun 2023 yakni 0,07 liter/detik.

c. Fasilitas pendidikan MTs. Al-Hidayah

Tabel 16. Kebutuhan air fasilitas pendidikan MTs. Al - Hidayah Desa Bulotalangi Timur

\begin{tabular}{|c|c|c|c|c|c|}
\hline No & Tahun & $\begin{array}{c}\text { Jumlah } \\
\text { Pelajar } \\
\text { (Orang) }\end{array}$ & $\begin{array}{c}\text { Konsumsi Air } \\
\text { Rata-Rata } \\
\text { (Ltoranghari) }\end{array}$ & $\begin{array}{c}\text { Jumlah } \\
\text { Pemakaian } \\
\text { (Lthari) }\end{array}$ & $\begin{array}{c}\text { Jumlah } \\
\text { Kebutuhan Air } \\
\text { (Liter:Detik) }\end{array}$ \\
\hline$[\mathrm{a}]$ & {$[\mathrm{b}]$} & {$[\mathrm{c}]$} & {$[\mathrm{d}]$} & {$[\mathrm{e}]$} & {$[\mathrm{f}]$} \\
\hline 1 & 2019 & 26 & 5 & 130 & 0,02 \\
\hline 2 & 2020 & 28 & 5 & 140 & 0,02 \\
\hline 3 & 2021 & 29 & 5 & 145 & 0,02 \\
\hline 4 & 2022 & 30 & 5 & 150 & 0,02 \\
\hline 5 & 2023 & 32 & 5 & 160 & 0,02 \\
\hline
\end{tabular}

Keterngan :

$[\mathrm{a}]=$ Nomor urut

$[b]=$ Tahun proyeksi (tahun perencanaan)

[c] = Jumlah pelajar tahun 2018 yaitu diperoleh dari sekolah MTs. Al- Hidayah Desa Bulotalangi
Timur. Perhitungan proyeksi pelajar dihitung menggunakan metode geometrik

$$
\begin{aligned}
& {[\mathrm{d}]=\text { Tabel } 3} \\
& {[\mathrm{e}]=[\mathrm{c}] \times[\mathrm{d}]} \\
& {[\mathrm{f}]=[\mathrm{e}] /(24 \times 60 \times 60)}
\end{aligned}
$$

Berdasarkan hasil analisis pada tabel 16 Menunjukkan bahwa pada Mts. Al - Hidayah Desa Bulotalangi Timur, untuk Fasilitas pendidikan pada tahun 2019 sampai dengan 2023 belum mengalami penungkatan atau konstan yaitu sebesar 0,02 liter/detik. Jadi kebutuhan air sektor non domestik untuk fasilitas pendidikan Desa Bulotalangi Timur secara keseluruhan ditunjukkan pada tabel 17.

Tabel 17. Jumlah kebutuhan air untuk fasilitas pendidikan Desa Bulotalangi Timur

\begin{tabular}{|c|c|c|c|c|}
\hline Tahun & $\begin{array}{c}\text { Kebutuhan Air } \\
\text { RA. Al-Hidayah } \\
\text { (Liter/Detik) }\end{array}$ & $\begin{array}{c}\text { Kebutuhan Air } \\
\text { MI. Al-Hidayah } \\
\text { (Liter/Detik }\end{array}$ & $\begin{array}{c}\text { Kebutuhan Air } \\
\text { MTs. Al- } \\
\text { Hidayah } \\
\text { (Liter/Detik }\end{array}$ & $\begin{array}{c}\text { Jumlah } \\
\text { (Liter/Detik) }\end{array}$ \\
\hline 2019 & 0,02 & 0,06 & 0,02 & 0,1 \\
\hline 2020 & 0,02 & 0,06 & 0,02 & 0,1 \\
\hline 2021 & 0,02 & 0,06 & 0,02 & 0,1 \\
\hline 2022 & 0,02 & 0,07 & 0,02 & 0,1 \\
\hline 2023 & 0,02 & 0,07 & 0,02 & 0,1 \\
\hline
\end{tabular}

2. Fasilitas peribadatan

Perhitungan kebutuhan air untuk masjid di tunjukkan pada tabel 18.

Tabel 18. Kebutuhan air untuk fasilitas peribadatan di Desa Bulotalangi Timur

\begin{tabular}{|c|c|c|c|c|c|}
\hline No & Tahun & $\begin{array}{c}\text { Jumlah } \\
\text { (Unit) }\end{array}$ & $\begin{array}{c}\text { Konsumsi Air } \\
\text { Rata-Rata } \\
\text { (Lt/unithari) }\end{array}$ & $\begin{array}{c}\text { Jumlah } \\
\text { Pemakaian } \\
\text { (Lt/Hari) }\end{array}$ & $\begin{array}{c}\text { Jumlah } \\
\text { Kebutuhan Air } \\
\text { (Liter/Detik) }\end{array}$ \\
\hline$[\mathrm{a}]$ & {$[\mathrm{b}]$} & {$[\mathrm{c}]$} & {$[\mathrm{d}]$} & {$[\mathrm{e}]$} & {$[\mathrm{f}]$} \\
\hline 1 & 2019 & 3 & 3000 & 9000 & 0,104 \\
\hline 2 & 2020 & 3 & 3000 & 9000 & 0,104 \\
\hline 3 & 2021 & 3 & 3000 & 9000 & 0,104 \\
\hline 4 & 2022 & 3 & 3000 & 9000 & 0,104 \\
\hline 5 & 2023 & 3 & 3000 & 9000 & 0,104 \\
\hline
\end{tabular}

Keterangan :

$[\mathrm{a}]=$ Nomor urut

$[\mathrm{b}]=$ Tahun proyeksi (tahun perencanaan)

[c] = Jumlah masjid tahun 2018 yaitu diperoleh dari hasil survai. Perhitungan jumlah masjid 
dihitung dengan asumsi seyiap lima tahun bertambah 1 unit di Desa Bulotalangi Timur.

$[\mathrm{d}]=$ Tabel 3

$[\mathrm{e}]=[\mathrm{c}] \mathrm{x}[\mathrm{d}]$

$[\mathrm{f}]=[\mathrm{e}] /(24 \times 60 \times 60)$

Berdasarkan kebutuhan air untuk fasilitas peribadatan di Desa Bulotalangi Timur beli mengalami peningkatan atau konstan, yaitu pada tahun 2019 sampai dengan 2023 sebesar 0,104 liter/detik.

\section{Fasilitas perkantoran}

Untuk fasilitas perkantoran diasumsikan untuk proyeksi jumlah pegawai perkantoran yaitu pada setiap 3 tahun pegawai bertambah 1 orang. Untuk fasilitas perkantoran Desa Bulotalangi Timur hanya memiliki 1 unit perkantoran saja yaitu kantor desa. Perhitungan kebutuhan air untuk fasilitas perkantoran ditunjukkan pada tabel 19.

Tabel 19 Kebutuhan Air fasilitas perkantoran desa Bulotalangi Timur

\begin{tabular}{|c|c|c|c|c|c|}
\hline No & Tahun & $\begin{array}{c}\text { Jumlah } \\
\text { Pegawai } \\
\text { (Orang) }\end{array}$ & $\begin{array}{c}\text { Konsumsi Air } \\
\text { Rata-Rata } \\
\text { (Lt jiwa/hari) }\end{array}$ & $\begin{array}{c}\text { Jumlah } \\
\text { Pemakaian } \\
\text { (Lt/Hari) }\end{array}$ & $\begin{array}{c}\text { Jumlah } \\
\text { Kebutuhan Air } \\
\text { (Liter/Detik) }\end{array}$ \\
\hline$[\mathrm{a}]$ & {$[\mathrm{b}]$} & {$[\mathrm{c}]$} & {$[\mathrm{d}]$} & {$[\mathrm{e}]$} & {$[\mathrm{f}]$} \\
\hline 1 & 2019 & 11 & 10 & 110 & 0,001 \\
\hline 2 & 2020 & 11 & 10 & 110 & 0,001 \\
\hline 3 & 2021 & 11 & 10 & 110 & 0,001 \\
\hline 4 & 2022 & 12 & 10 & 120 & 0,001 \\
\hline 5 & 2023 & 12 & 10 & 120 & 0,001 \\
\hline
\end{tabular}

Keterangan :

[a] = Nomor urut

$[\mathrm{b}]=$ Tahun proyeksi (tahun perencanaan)

[c] = Jumlah pegawai perkantoran tahun 2019 diperoleh dari hasil survai. Proyeksi jumlah pegawai perkantoran diasumsikan bertambah 1 pegawai setiap jangka waktu 3 tahun

$[\mathrm{d}]=$ Tabel 3

$[\mathrm{e}]=[\mathrm{c}] \mathrm{x}[\mathrm{d}]$

$[\mathrm{f}]=[\mathrm{e}] /(24 \times 60 \times 60)$
Berdasarkan tabel 19 menunjukkan jumlah kebutuhan air pada fasilitas perkantoran dari tahun 2019 sampai dengan 2023 belum mengalami peningkatan atau konstan yaitu sebesar 0,001 liter/detik.

\section{Fasilitas kesehatan}

Perkembangan fasilitas kesehatan sampai tahun 2023 diasumsikan bersifat konstan, artinya tidak ada pertambahan untuk fasilitas ini. Maka jumlah kebutuhan air untuk fasilitas ini tetap dari tahun 2019 sampai dengan 2023. Berikut adalah hasil analisis kebutuhan air untuk fasilitas puskesmas ditunjukkan pada tabel 20.

Tabel 20. Kebutuhan Air Fasilitas Kesehatan Desa Bulotalangi Timur

\begin{tabular}{|c|c|c|c|c|c|}
\hline No & Tahun & $\begin{array}{l}\text { Jumlah } \\
\text { (Unit) }\end{array}$ & $\begin{array}{l}\text { Ronsum si Air } \\
\text { Rata-Rata } \\
\text { (Ltjiwahari) } \\
\end{array}$ & $\begin{array}{c}\text { Jumlah } \\
\text { Pemakaian } \\
\text { (LtHari) }\end{array}$ & $\begin{array}{c}\text { Jumlah } \\
\text { Kebutuhan Air } \\
\text { (Liter Detik) }\end{array}$ \\
\hline [a] & [b] & [c] & [d] & [e] & [f] \\
\hline 1 & 2019 & 1 & 2000 & 2000 & 0,023 \\
\hline 2 & 2020 & 1 & 2000 & 2000 & 0,023 \\
\hline 3 & 2021 & 1 & 2000 & 2000 & 0,023 \\
\hline 4 & 2022 & 1 & 2000 & 2000 & 0,023 \\
\hline 5 & 2023 & 1 & 2000 & 2000 & 0,023 \\
\hline
\end{tabular}

Keterangan :

[a] $=$ Nomor urut

[b] = Tahun proyeksi (tahun perencanaan)

[c] = Jumlah fasilitas kesehatan tahun 2019 yaitu 1 unit di peroleh dari hasil survai. Perhitungan proyeksi jumlah fasilitas kesehatan diasumsikan konstan.

$[\mathrm{d}]=$ Tabel 3

$[\mathrm{e}]=[\mathrm{c}] \mathrm{x}[\mathrm{d}]$

$[\mathrm{f}]=[\mathrm{e}] /(24 \times 60 \times 60)$

Berdasarkan Tabel 20 Menunjukkan jumlah kebutuhan air untuk fasilitas kesehatan di Desa Bulotalangi Timur Dari Tahun 2019 sampai 
dengan tahun 2023 konstan yaitu sebesar 0,023 liter/detik.

\section{d. Kebutuhan Air Bersih Desa Bulotalangi Timur}

Setelah mendapatkan hasil perhitungan kebutuhan air bersih sektor domestik dan kebutuhan air bersih sektor non domestik di Desa Bulotalangi Timur yang ditinjau, kemudian dibuatkan tabel jumlah total kebutuhan air bersih di desa yang ditinjau. Jumlah total kebutuhan air bersih dapat ditunjukkan pada tabel 21 .

Tabel 21. Jumlah total kebutuhan air bersih di Desa Bulotalangi Timur

\begin{tabular}{|c|c|c|c|c|c|c|c|}
\hline Tahun & $\begin{array}{c}\text { SR } \\
\text { (It/detik) }\end{array}$ & $\begin{array}{c}\text { HU } \\
\text { (lt/detik) }\end{array}$ & $\begin{array}{c}\text { Pendidi } \\
\text { kan } \\
\text { (lt/detik) }\end{array}$ & $\begin{array}{c}\text { Peribada } \\
\text { tan } \\
\text { Masjid } \\
\text { (ltdetik) }\end{array}$ & $\begin{array}{c}\text { Perkant } \\
\text { oran } \\
\text { (ltdetik) }\end{array}$ & $\begin{array}{c}\text { Kesehat } \\
\text { an } \\
\text { (ttddetik) }\end{array}$ & $\begin{array}{c}\text { Jumlah } \\
\text { (lt/detik) }\end{array}$ \\
\hline 2019 & 0,585 & 0,107 & 0,1 & 0,104 & 0,001 & 0,023 & 0,920 \\
\hline 2020 & 0,596 & 0,110 & 0,1 & 0,104 & 0,001 & 0,023 & 0,934 \\
\hline 2021 & 0,609 & 0,112 & 0,1 & 0,104 & 0,001 & 0,023 & 0,949 \\
\hline 2022 & 0,621 & 0,114 & 0,1 & 0,104 & 0,001 & 0,023 & 0,963 \\
\hline 2023 & 0,633 & 0,116 & 0,1 & 0,104 & 0,001 & 0,023 & 0,977 \\
\hline
\end{tabular}

Berdasarkan Tabel 21 Menunjukkan jumlah kebutuhan air bersih di Desa Bulotalangi Timur mengalami peningkatan setiap tahunnya.pada tahun 2019 kebutuhan air bersih sebesar 0,920 liter/detik keudian meningkat pada tahun 2023 sebesar 0,977 liter/detik.

Dalam melakukan analisis berikutnya maka dari hasil perhitungan total kebutuhan air bersih (kebutuhan normal) di Desa Bulotalangi Timur selanjutnya dihitung untuk kebutuhan air bersih pada harian maksimum dan jam puncak. Pada analisis tersebut dibuat tabel rekapitulasi kebutuhan air di Desa Bulotalangi Timur, untuk lebih jelasnya dapat ditunjukkan pada tabel 22.
Tabel 22 Rekapitulasi kebutuhan air bersih

\begin{tabular}{|c|c|c|c|c|c|c|}
\hline & Faktor & 2019 & 2020 & 2021 & 2022 & 2023 \\
\hline $\begin{array}{c}\text { Normal } \\
\text { (lt/detik) }\end{array}$ & 1 & 0,920 & 0,934 & 0,949 & 0,963 & 0,977 \\
\hline $\begin{array}{c}\text { FHM } \\
\text { (lt/detik) }\end{array}$ & 1,15 & 1,058 & 1,074 & 1,091 & 1,107 & 1,124 \\
\hline $\begin{array}{c}\text { FJP } \\
\text { (lt/detik) }\end{array}$ & 1,75 & 1,610 & 1,635 & 1,661 & 1,685 & 1,710 \\
\hline
\end{tabular}

Keterangan:

$\mathrm{FHM}=$ Faktor Harian Maksimum (liter/detik)

FJP $=$ Faktor Jam Puncak (liter/detik)

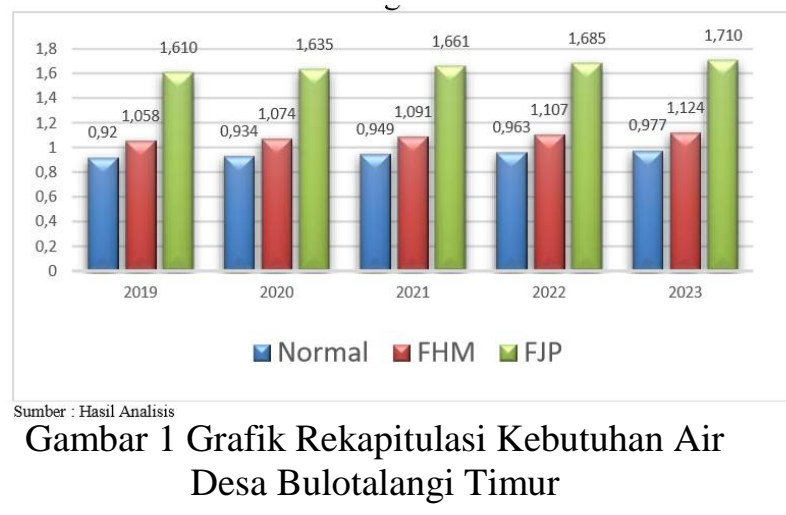

Berdasarkan Gambar 1 menunjukkan rekapitulasi kebutuhan air di Desa Bulotalangi Timur mengalami peningkatan setiap tahunnya. Kebutuhan air maksimum pada tahun 2019 sebesar 1,058 liter/detik kemudian meningkat pada tahun 2023 sebesar 1,124 liter/detik. Serta kebutuhan air jam puncak pada tahun 2019 sebesar 1,610 liter/detik kemudian meningkat pada tahun 2023 sebesar 1,710 liter/detik.

\section{Pembahasan}

\section{a. Sistem Penyediaan Air Bersi Desa Bulotalangi Timur}

Penyediaan air bersih di daerah penelitian dapat dilihat dari dua aspek yaitu aspek potensi dan aspek kendala (hambatan).

\section{Aspek Potensi}


Aspek potensi dalam penyediaan air bersih di Desa Bulotalangi Timur yaitu kurangnya ketersediaan sumber air bersih.

\section{Aspek Kendala}

Aspek kendala penyediaan air bersih yang ada di Desa bulotalangi Timur yang ditinjau terapat dua hal yaitu :

a. Aspek teknis yaitu :

1. Desa Bulotalangi Timur terdapat sumber air tanah yang bisa digunakan. Akan tetapi, oleh karena letak topografi desa yang berada di kaki gunung menyebabkan tingginya muka air tanah sehingga sumur gali masyarakat mencapai kedalamn 12 meter. Hal ini juga menyebabkan sumber air mengalami kekeringan saat musim kemarau tiba. Sumber air lainnya yakni sumur pompa yang sebagian merupakan bantuan dari pemerintah. Sumur pompa ini memiliki kedalaman hingga mencapai 28 meter. Karena kedalaman nya sangat tinggi, diperlukan pula mesin pompa yang berukuran agak besar untuk memompakan air.

2. Berdasarkan hasil analisis, kebutuhan air bersih di Desa Bulotalangi Timur pada tahun 2023 untuk Faktor Harian Maksimum (FHM) sebesar 1,124 liter/detik dan Faktor Jam Puncak (FJP) sebesar 1,710 liter/detik. Dengan melihat kondisi eksisting desa bulotalangi timur yang berada di kaki gunung, kebutuhan air di Desa Bulotalangi Timur sampai tahun 2023 belum bisa terpenuhi khususnya pada musim kemarau atau saat hujan tidak turun pada kurun waktu tertentu. Sedangkan pada musim hujan, kebutuhan air di Desa tersebut dapat terpenuhi.
Hal ini karena kondisi sumber-sumber air bersih yang ada di Desa Bulotalangi Timur belum bisa memenuhi kebutuhan air di desa tersebut.

b. aspek non teknis yaitu kurangnya kepedulian masyarakat terhadap sumber-sumber air dan juga ekonomi masyarakat masih kurang mampu mengelola sumber air. Hal ini dikarenakan ratarata masyarakat memiliki mata pencaharian yang tidak tetap atau kurang mampu.

\section{KESIMPULAN}

Berdasarkan hasil penelitian di peroleh bahwa, kondisi eksisting sistem penyediaan air bersih di Desa Bulotalangi Timur kecamatan Bulango Timur Kabupaten Bone Bolango belum memenuhi persyaratan teknis luas arel dan populasi. Hal ini karena kondisi sumber-sumber air bersih belum bisa memenuhi kebutuhan air di desa tersebut.

Berdasarkan hasil analisis, total kebutuhan air di Desa Bulotalangi timur untuk faktor jam puncak pada tahun 2023 yaitu sebesar 1,710 liter/detik. Dengan demikan maka kebutuhan air di Desa bulotalangi Timur Kecamatan Bulango Timur Kabupaten Bone Bolango sampai tahun 2023 belum bisa terpenuhi.

\section{SARAN}

1. Desa Bulotalangi Timur memerlukan penambahan, peremajaan sambungan pipa untuk mata air, hidran umum agar kebutuhan air bersih masyarakat dapat terlayani. 
2. Untuk pemerintah atau instansi terkait yang mengelola sistem penyediaan air bersih di Desa Bulotalangi Timur, agar kiranya dapat meninjau daerah yang memerlukan air bersih untuk kebutuhan sehari-hari dan belum terjangkau oleh sistem jaringan pipa, serta meningkatkan pelayanan akan kebutuhan air sehingga keluhan akan air bersih dapat teratasi.

3. Bagi masyarakat sebagai konsumen agar kiranya dapat memelihara sumber-sumber air bersih sehingga dapat digunakan untuk jangka panjang .

\section{DAFTAR PUSTAKA}

Anonim. 1990. Peraturan Menteri Kesehatan Republik Indonesia Nomor 416/Menkes/Per/IX/2010 tentang Syaratsyarat dan Pengawasan Kualitas Air. Jakarta

Anonim. 2010. Peraturan Menteri Kesehatan Republik Indonesia Nomor 492/Menkes/Per/IV/2010 tentang Persyaratan Kualitas Air Minum. Jakarta Departemen Pekerjaan Umum. 2000. Kriteria Perencanaan Ditjen Cipta Karya. Jakarta

Handayani, Novi. 2010. Studi Awal Tentang Sistem Penyediaan Air Bersih Di Desa Karangduwur Kecamatan Kalikajar Kabupaten Wonosobo. Semarang

Hericah, Yolanda. 2015. Perencanaan Jaringan Pipa Distribusi Air Bersih Kelurahan Pipa Reja Kecamatan Kemuning Palembang. Palembang

Heryono, Cahyo A. 2017. Studi Perencanaan Sistem Penyediaan Air Bersih Untuk Desa Umbulan Kecamatan Winongan Kabupaten Pasuruan. Malang

Khoirillah, Najiatul, MSY. 2015. Perencanaan Jaringan Pipa Distribusi Air Bersih Di
Kelurahan Talang Semut Palembang. Palembang

Kristia, Merida. 2016. Perencanaan Sistem Penyediaan Air Baku Di Kecamatan Punduh Pidada Dan Kecamatan Padang Cermin Kabupaten Pesawaran. Bandar Lampung

Linsley, Ray K. and Franzini, Joseph B. 1986. Teknik Sumber Daya Air Jilid 2. Erlangga: Jakarta Masduki,Ali. 2013. Teknologi Penyediaan Air Bersih Pedesaan Studi Kasus Di Kabupaten Mojokerto. Surabaya

Moegijantoro. 1995. Prospek Penyediaan Air Baku Dalam Pengembangan Air di SWS Bengawan Solo, Seminar Sehari FTSP UUII Dies Ke-52 UII

Nitya, Rida. 2014. Perencanaan Distribusi Air Bersih Di Kelurahan Lembung Gajah Kecamatan Sematang Borang Kota Palembang. Palembang

Rezky, Intan Sari. 2015. Perencanaan Siistem Jaringan Pipa Distribusi Air Bersih Di Kelurahan Sukarami Kecamatan Sukarami Palembang. Palembang

Sarwoko, Mangkudiharjo, Penyediaan Air Bersih I: Dasar-dasar Perencanaan dan Evaluasi Kebutuhan Air. Teknik Penyehatan: Institut Teknologi Sepuluh November Surabaya

Slamet, 2004, Kesehatan Lingkungan, Yogyakarta: UGM press

Sutrisno, Muhammad. 1996. Sumur Gali Sumber Air Bersih. Udayana Press, Denpasar 